\title{
Thermal Changes following Er,Cr:YSGG Laser Irradiation through a Translucent Zirconia
}

\author{
Holly Raymond ${ }^{1}$, Lauren Rae Corby $^{2}$ and Susana Maria Salazar Marocho ${ }^{3, *}$ \\ ${ }^{1}$ School of Dentistry, University of Mississippi Medical Center, Jackson, MS, USA \\ ${ }^{2}$ Biomedical Materials Science Department, School of Dentistry, University of Mississippi Medical Center, Jackson, MS, USA; \\ Environmental Science Department, Jackson State University, Jackson, MS, USA \\ ${ }^{3}$ Biomedical Materials Science Department, School of Dentistry, University of Mississippi Medical Center, Jackson, MS, USA
}

*Corresponding author: Susana M. Salazar Marocho, Department of Biomedical Materials Science, University of Mississippi Medical Center, 2500 North State Street, Jackson, MS, USA, Tel: +1 6019846170

Received date: 11 June, 2021 | Accepted date: 9 July, 2021 | Published date: 13 July, 2021

Citation: Raymond H, Corby LR, Marocho SMS (2021) Thermal Changes following Er,Cr: Ysgg Laser Irradiation through A Translucent Zirconia. J Dent Oral Epidemiol 1(1). doi https://doi.org/10.54289/JDOE2100102

Copyright: () 2021 Raymond H, et al. This is an open-access article distributed under the terms of the Creative Commons Attribution License, which permits unrestricted use, distribution, and reproduction in any medium, provided the original author and source are credited.

Abbreviations: YSZ: Yttria-stablilized zirconia

\section{Introduction}

Yttria-stablilized zirconia (YSZ) is increasing in popularity among dentists due to its ability to be used as a monolithic restoration [1]. Monolithic zirconia restorations have combined better esthetics and strength than other toothcolored restorations, making them an attractive and convenient choice by dentists and patients $[2,3]$.

Single- and multiple-unit restorations such as abutments, implant supported prosthesis, and orthodontic brackets are examples of zirconia's use in clinical practice [1]. Material complications for monolithic YSZ restorations are minimal; $[4,5]$ however, biological and technical complications such as recurrent decay, cementation errors, iatrogenic causes, endodontic access, esthetic failure, and occlusal issues, to name a few, occur more often [2]. Any of those circumstances required the removal or replacement of the restoration. Typically, coarse tapered or cylindrical diamond burs on a high-speed handpiece are used to remove failed ceramic restorations $[2,6]$ that are still in place. In single crowns, the process starts by sectioning the buccal and lingual surfaces to break into two pieces the cemented restoration that can later be removed using a crown separator [2]. This multi-step instrumentation represents a risk for damage to the soft and hard tissues, e.g., the harm of the gingiva, removal of unnecessary tooth structure, high heat causing pulpal necrosis, tooth fracture, or even damage to an adjacent tooth [2]. To prevent these undesirable damages, removing fixed restorations using dental lasers is becoming an area of interest.

In a case report by Cranska in 2016, an Er: YAG laser was used to debond still bonded remnants of a fractured monolithic YSZ crown without damage to the underlying tooth structure. The removal of the crown was completed in $120 \mathrm{~s}$ [7] without apparently being traumatic to the underlying tooth structure. Other clinical cases have shown that no tooth structure is damaged during removal of the monolithic zirconia restoration and that the restoration remains in a single piece without surface alterations [2]. The effectiveness of the clinical use of the lasers on monolithic restorations is an unexplored but important area to unveil considering the increasing number of monolithic restorations bonded to the tooth or implant abutments using resin-based cements $[\mathbf{1 , 8}$ - 
11]. There are clinical reports on the debonding capabilities of the erbium-based lasers, but there is no research about the thermal effects on high strength ceramics. Thus, the temperature changes were assessed during laser application through a translucent monolithic YSZ ceramic.

Materials and Methods
Translucent YSZ (InCoris TZI, Dentsply Sirona) blocks were cut using an automated cutting machine (Accutom 50, Struers) and a diamond blade. Slices were sintered at $1500^{\circ} \mathrm{C}$ in a high-temperature furnace (Sintramat $240 \mathrm{~V}$, Ivoclar Vivadent). The sintered slices were assigned to three groups $(\mathrm{n}=10)$ according to their final thicknesses of $0.5,1.0$, and $2.0 \mathrm{~mm}$ (Figure 1).

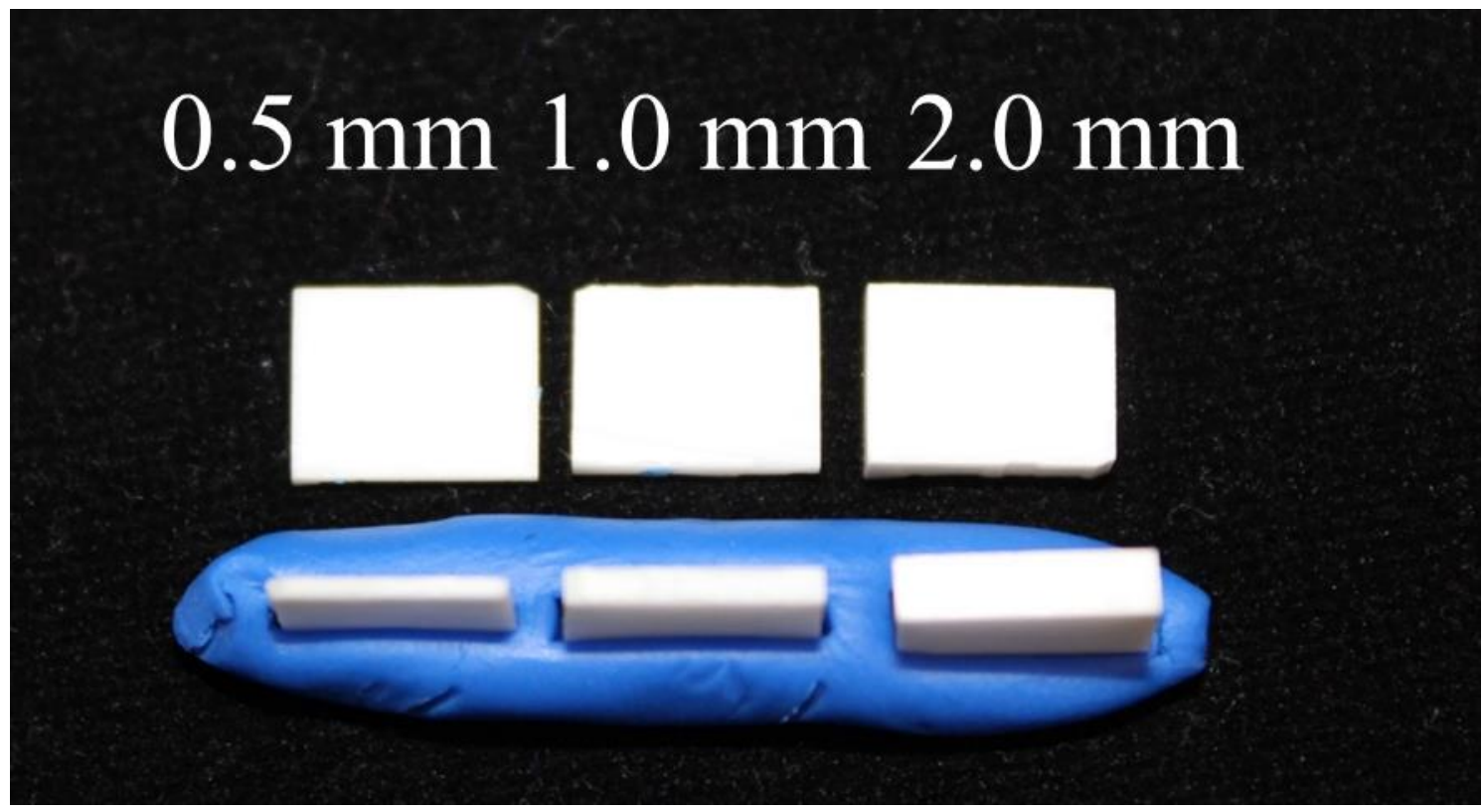

Figure 1: YSZ slices with different thicknesses.

Every sample was irradiated using the Er, Cr: YSGG laser (Waterlase $\mathrm{MD}^{\mathrm{TM}}$, Biolase) at $1 \mathrm{~W}$ and 45 pulses per second, without irrigation. The MG6 tip was held perpendicular to the ceramic surface while the temperature was measured using a type $\mathrm{K}$ thermocouple on the ceramic sample's underside (Figure 2). The temperature was recorded in Celsius $\left({ }^{\circ} \mathrm{C}\right)$ with a digital thermometer (OMEGA HH506R) every 30, 60, 90 , and $120 \mathrm{~s}$.

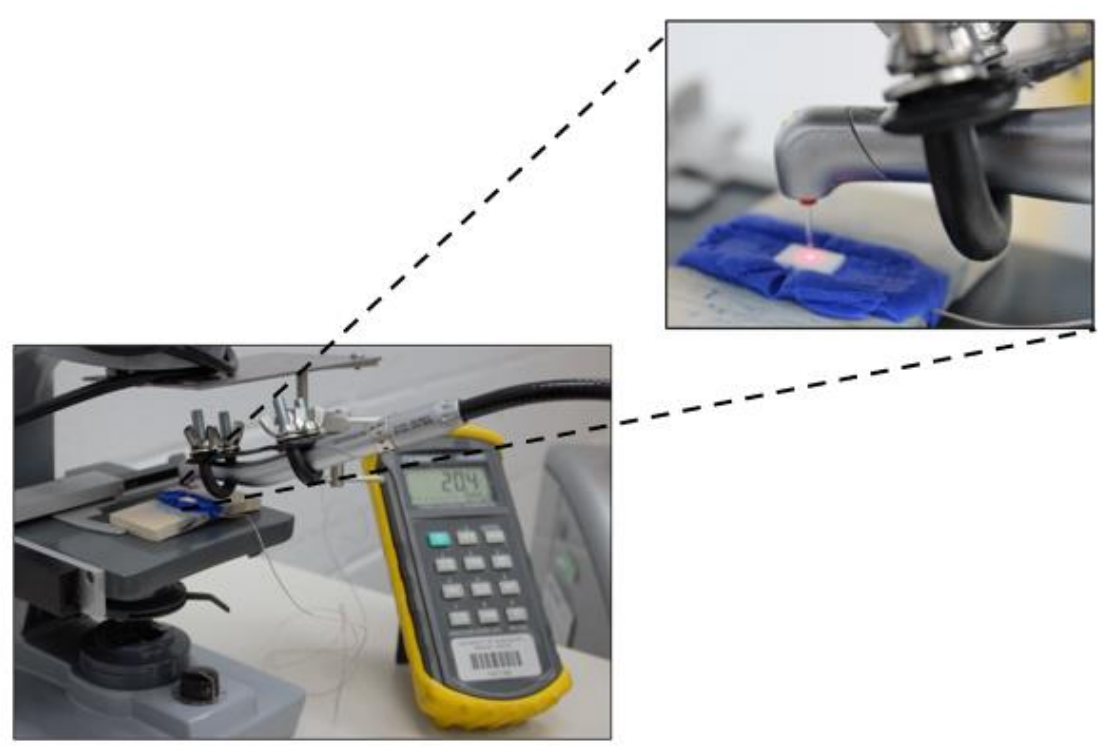


Figure 2: View of the laser irradiation set up consisting of the thermometer, thermocouple, laser handpiece, and YSZ slice. The magnified figure shows the laser tip held perpendicular to the YSZ surface fixed on blue polymer clay. The thermocouple can be seen running under the YSZ slice, aligned and below the laser tip to measure the transmitted temperature.

Statistical analysis was performed using SigmaPlot software (Systat Software Inc., San Jose, California, USA). One-way repeated measures ANOVA was used to analyze statistical differences among the means of the groups followed by a post-hoc Tukey test. The significance level was set at $\alpha=0.05$.

\section{Results}

The mean maximum temperature and standard deviation for each group after 30, 60, 90, and $120 \mathrm{~s}$ are listed in Table 1.

\begin{tabular}{|c|c|c|c|c|}
\hline \multirow{2}{*}{$\begin{array}{l}\text { Groups } \\
(\mathbf{n}=\mathbf{1 0})\end{array}$} & \multicolumn{4}{|c|}{$\begin{array}{l}\text { Temperature in }{ }^{\circ} \mathrm{C} \\
\text { (Standard deviation) }\end{array}$} \\
\hline & After $30 \mathrm{~s}$ & After $60 \mathrm{~s}$ & After $90 \mathrm{~s}$ & After $120 \mathrm{~s}$ \\
\hline $0.5 \mathrm{~mm}$ & $\begin{array}{l}63.9 \\
(7.5)\end{array}$ & $\begin{array}{l}73.3 \\
(6.8)\end{array}$ & $\begin{array}{l}78.9 \\
(8.0)\end{array}$ & $\begin{array}{l}82.0 \\
(7.9)\end{array}$ \\
\hline $1.0 \mathrm{~mm}$ & $\begin{array}{l}40.9 \\
(3.2)\end{array}$ & $\begin{array}{l}45.3 \\
(3.9)\end{array}$ & $\begin{array}{l}48.4 \\
(4.1)\end{array}$ & $\begin{array}{l}50.7 \\
(4.1)\end{array}$ \\
\hline $2.0 \mathrm{~mm}$ & $\begin{array}{l}34.2 \\
(1.0)\end{array}$ & $\begin{array}{l}38.3 \\
(1.1)\end{array}$ & $\begin{array}{l}40.8 \\
(1.3)\end{array}$ & $\begin{array}{l}42.7 \\
(1.4)\end{array}$ \\
\hline
\end{tabular}

Table 1: Temperature data $\left(\right.$ in ${ }^{\circ} \mathrm{C}$ ) after four periods of continuous laser irradiation

One-way repeated measures ANOVA determined there was a significant difference between the temperature values through each YSZ thickness at each irradiation time $(\mathrm{p}<0.001)$. The highest temperature was recorded after $120 \mathrm{~s}$ of laser irradiation. The temperature was significantly different among the three thicknesses $(0.5 \mathrm{~mm}$ vs $1 \mathrm{~mm}, \mathrm{p}=0.001,0.5$ $\mathrm{mm}$ vs $2 \mathrm{~mm}, \mathrm{p}=0.001,1 \mathrm{~mm}$ vs $2 \mathrm{~mm}, \mathrm{p}=0.006$ ).

\section{Discussion}

The laser-induced debonding has been widely investigated for ceramic orthodontic brackets rather than ceramic restorations [12-16]. Although the tested parameters and strategies of erbium-based lasers are safe for removing or debonding ceramic brackets, they remain unexplored for the second generation of yttria content partially stabilized translucent zirconia ceramics, thus require further investigation. Our study details the thermal changes produced by an Er, Cr: YSGG laser through a translucent monolithic YSZ ceramic upon constant laser irradiation.

For all the YSZ thicknesses investigated, $0.5 \mathrm{~mm}, 1 \mathrm{~mm}$, and $2 \mathrm{~mm}$, irradiation time did not affect temperature, except at 120 seconds, which was significantly higher than the one after a $30 \mathrm{~s}$ period. These results suggest that there is the potential for high temperatures after long constant irradiation at thin and thick thicknesses of the YSZ ceramic, where the laser energy is absorbed and turned into heat that reached the counter side of the irradiated area on the ceramic surface. Very few studies have been performed to study the effects of transmitted laser energy through translucent monolithic YSZ ceramics. The maximum temperature transferred through a 1 mm thickness opaque YSZ ceramic using the Er, Cr: YSGG laser at low power without irrigation is in agreement with the values obtained in the present study [Corby, et al.]. This implies that the laser strategy proposed can be suitable for both types of YSZ ceramics, translucent and opaque, despite their difference in alumina content that accounts for the degree of translucency of the material $[\mathbf{1 7}, \mathbf{1 8}]$. Through the thickest YSZ thickness investigated in this study $(2 \mathrm{~mm})$, the lowest heat was transmitted compared to the other groups, suggesting that the thicker polycrystalline layer contributed to less transmission of energy through the structure. In a comprehensive review by Kellesarian et al. [19], it was determined that the removal of YSZ restorations varied from 30 to $120 \mathrm{~s}$ [20] whereas the removal of lithium disilicate veneers with less than $1 \mathrm{~mm}$ of thickness, can take 9 to $15 \mathrm{~s}$ [21] using Er, Cr: YSGG and Er: YAG lasers, respectively. This clinical report evidence was the basis for the laser irradiation time evaluated in this study. 
In dentistry, time plays an important role in clinical practice. This is why using a laser instead of rotary mechanical instrumentation for removal of high-strength ceramic restorations reduces the time that the clinician spends in this process while avoiding iatrogenic damage to the underlying structure, and reducing the fatigue and anxiety of the patient. Our results showed that potentially the Er, Cr: YSGG laser parameters chosen in this research could result in different ranges of temperatures depending on the ceramic thickness. On one side, the increase in temperature for groups 0.5 and 1 $\mathrm{mm}$ can create a hostile environment to the dental pulp.

On the other side, the temperature changes remain gentle and could be clinically applicable for the removal of $2 \mathrm{~mm} \mathrm{YSZ}$ structures.

The use of laser as a softening method for the resin cement used for high-strength ceramics such as YSZ can potentially have the advantage of being faster than other methods. In a study by Millar, 35 dentists took $39 \mathrm{~s}$ on average to cut a 1 $\mathrm{mm}$ groove into a YSZ ceramic using the most effective bur, and $53 \mathrm{~s}$ on average with the least effective bur [22]. If a posterior YSZ restoration is planned to be removed, then the time can triplicate because the $1 \mathrm{~mm}$ groove will need to be cut on the buccal, occlusal, and lingual surfaces; besides the fact that the cutting effectiveness of the bur is compromised, decreasing rapidly. Using a laser would allow for more timeeffective crown removal compared to the use of diamond burs, but further studies need to be performed on this.

Laser removal of monolithic or so-called full-contour YSZ crowns is intended to be a conservative method. This method allows for the removal of the restoration in a single piece and possible reuse as a temporary or final restoration depending on the clinical circumstance. Despite our study did not aim to assess color changes after the laser irradiation, the here tested removal laser parameters seemed not to affect the color of the translucent YSZ ceramic to the naked eye, which in the case of reusing laser debonded anterior restorations would be very favorable.

The selection of laser settings is a critical parameter that, if not chosen adequately, would have a high impact on the restoration followed by the underlying abutment and surrounding tissues. Using Er, Cr: YSGG lasers to debond
YSZ restorations, is a great advancement for clinical dentist practice. The removal of a YSZ monolithic crown with a diamond bur takes clinicians more time and causes destruction of the crown, while the use of laser would provide a more efficient and conservative method. Further research of the laser parameters and time used in this study on bonded translucent YSZ structures could lead to a better understanding of the factors controlling the debonding mechanism.

In summary, as the translucent YSZ ceramic thickness increased, the $\mathrm{T}$ decreased significantly at each irradiation time. Although laser irradiation generated a significantly higher temperature, it remained below the critical value when $2 \mathrm{~mm}$ thickness translucent YSZ was used and may be considered safe for use.

Author Disclosure Statement: No conflicting financial interests exist.

Acknowledgements: The authors acknowledge support from the Intramural Research Support Program, UPSTART program and Biomedical Materials Science Shared Equipment Facility at School of Dentistry, University of Mississippi Medical Center.

\section{References}

1. Sulaiman TA, Abdulmajeed AA, Donovan TE, Cooper LF, Walter R (2016) Fracture rate of monolithic zirconia restorations up to 5 years: A dental laboratory survey. J Prosthet Dent 116(3): 436-439.

2. Spath A, Smith C (2017) Removal of Modern Ceramics. Compend Contin Educ Dent 38(5): 326-333.

3. Christensen GJ (2009) Porcelain-Fused-to-Metal Versus Zirconia-Based Ceramic Restorations. J Am Dent Assoc 140(8): 1036-1039.

4. Tang Z, Zhao X, Wang H, Liu B (2019) Clinical evaluation of monolithic zirconia crowns for posterior teeth restorations, Medicine 98(40): e17385.

5. Bidra AS, Tischler M, Patch C (2018) Survival of 2039 complete arch fixed implant-supported zirconia prostheses: A retrospective study. J Prosthet Dent 119(2): 220-224. 
6. Engelberg B (2013) An Effective Removal System for Zirconia and Lithium-Disilicate Restorations. Inside Dentistry 9(2).

7. Cranska JP (2015) Laser Removal of All-Ceramic Restorations. Solving a Difficult Clinical Challenge. Dent Today 34(3): 110-113.

8. Limmer B, Sanders AE, Reside G, Cooper LF (2014) Complications and patient-centered outcomes with an implant-supported monolithic zirconia fixed dental prosthesis: 1 year results. J Prosthodont 23(4): 267-275.

9. Cheng $\mathrm{CW}$, Chien $\mathrm{CH}$, Chen $\mathrm{CJ}$, Papaspyridakos $\mathrm{P}$ (2018) Clinical Results and Technical Complications of Posterior Implant-Supported Modified Monolithic Zirconia Single Crowns and Short-Span Fixed Dental Prostheses: A 2-Year Pilot Study. J Prosthodont 27(2):108-114.

10. Cheng $\mathrm{CW}$, Chien $\mathrm{CH}$, Chen $\mathrm{CJ}$, Papaspyridakos $\mathrm{P}$ (2019) Randomized Controlled Clinical Trial to Compare Posterior Implant-Supported Modified Monolithic Zirconia and Metal-Ceramic Single Crowns: One-Year Results. J Prosthodont 28(1): 15-21.c

11. Degidi M, Nardi D, Gianluca S, Piattelli A (2018) The Conometric Concept: A 5-Year Follow-up of Fixed Partial Monolithic Zirconia Restorations Supported by Cone-in-Cone Abutments. Int J Periodontics Restorative Dent 38(3): 363-371.

12. Nalbantgil D, Oztoprak MO, Tozlu M, Arun T (2011) Effects of different application durations of ER: YAG laser on intrapulpal temperature change during debonding. Lasers Med Sci 26(6):735- 740.

13. Nalbantgil D, Tozlu M, Oztoprak MO (2014) Pulpal thermal changes following Er-YAG laser debonding of ceramic brackets. ScientificWorldJournal 912429.
14. Rechmann P, Buu NCH, Rechmann BMT, Finzen FC (2015) Laser all-ceramic crown removal and pulpal temperature--a laboratory proof-of-principle study. Lasers Med Sci 30(8): 2087-2093.

15. Nalbantgil D, Tozlu M, Oztoprak MO (2018) Comparison of different energy levels of Er:YAG laser regarding intrapulpal temperature change during safe ceramic bracket removal. Photomed Laser Surg 36(4):209-213.

16. Grzech-Leśniak K, Matys J, Żmuda-Stawowiak D, Mroczka K, Dominiak M, et al. (2018) Er:YAG Laser for metal and ceramic bracket debonding: An In Vitro study on intrapulpal temperature, SEM, and EDS analysis. Photomed Laser Surg 36(11): 595-600.

17. Zhang Y, Lawn BR (2018) Novel Zirconia Materials in Dentistry. J Dent Res 97(2):140-147.

18. Tong H, Tanaka CB, Kaiser MR, Zhang Y (2016) Characterization of three commercial Y-TZP ceramics produced for their high translucency. Ceram Int 42(1 Pt B): 1077-1085.

19. Kellesarian SV, Malignaggi VR, Aldosary KM, Javed F (2018) Laser-assisted removal of all ceramic fixed dental prostheses: A comprehensive review. J Esthet Restor Dent 30(3): 216-222.

20. Broome PJ (2007) Utilization of an Er, Cr:YSGG laser for the removal of all-ceramic restorations. Pract Proced Aesthet Dent 19(1): 23-25.

21. Kursoglu P, Gursoy H (2013) Removal of fractured laminate veneers with Er:YAG laser: report of two cases. Photomed Laser Surg 31(1): 41-43.

22. Millar B (2017) An Assessment of burs designed to cut zirconia. Open Journal of Stomatology 7(5): 277-288. 